Gut, 1981, 22, 120-125

\title{
Dinitrochlorobenzene-induced colitis in the guinea-pig: studies of colonic lamina propria lymphocytes*
}

\author{
M E GLICK† AND Z M FALCHUK†
}

From the Department of Medicine, Brigham and Women's Hospital and Harvard Medical School, Boston, Massachusetts, USA

SUMMARY Dinitrochlorobenzene-induced colitis in guinea-pigs may be immunologically mediated: animals must be presensitised to dinitrochlorobenzene to develop colitis, sensitivity can be passively transferred by lymphocytes and the injury can be mitigated by immunosuppression. In this study, we examined lamina propria lymphocytes isolated from colons of animals with dinitrochlorobenzeneinduced colitis, and appropriate controls. Lamina propria lymphocytes from colitis animals have a greater percentage of rabbit erythrocyte-rosetting cells ( $\mathrm{T}$ cells) $(20 \cdot 1 \pm 3.0 \mathrm{vs} 2 \cdot 3 \pm 0 \cdot 8, \mathrm{P}<\cdot 01)$ and a greater capacity to mediate mitogen-induced cellular cytotoxicity with phytohaemagglutinin than lamina propria lymphocytes from normal colon $(\%$ specific cytoxicity $=29 \cdot 4 \pm 8 \cdot 7$ vs $5 \cdot 0 \pm 4 \cdot 5$, $\mathrm{P}<\cdot 005$ ). There was no difference in the percentage of rosetting cells or cytotoxicity index of spleen or mesenteric lymph node lymphocytes between the colitis animals and controls. These data suggest that there are changes in the distribution and functional characteristics of lamina propria lymphocytes which correlate with mucosal cell injury in the dinitrochlorobenzene-colitis model.

There are a growing number of experimental animal models of inflammatory bowel disease. ${ }^{1-5}$ Among the best characterised of these is the model in which the colitis is induced by rectal instillation of 2,4-dinitro-1chlorobenzene (DNCB) into presensitised guineapigs or rabbits. ${ }^{2}{ }^{6}$

DNCB is a chemical hapten which binds to tissue protein and is capable of inducing delayed-type hypersensitivity when applied to the skin or the intestinal mucosa. In the skin, the pathological lesion is a small vessel vasculitis involving the dermis and the subcutaneous tissue. A mononuclear cellular infiltration occurs around the venules, along with endothelial proliferation. There is little fibrosis or necrosis. In the large bowel, DNCB-induced colitis has some of the histological features associated with idiopathic human colitis. The lesion is characterised

\footnotetext{
*Published in Abstract form (Gastroenterology, $76: 1139$ 1979). +Present address: University of California at Irvine Veterans Administration Medical Center, Long Beach, California 90822, USA.

$\ddagger$ Address for reprint requests and correspondence: Dr Z Myron Falchuk, Brigham and Women's Hospita!, 75 Francis Street, Boston, Massachusetts 02115, USA.

Dr Falchuk is supported in part by NIH Grant AM 17684 and Research Career Development Award, AM 00210.
}

Received for publication 15 September 1980 by a mononuclear cell infiltration, vascular congestion, and perivascular cuffing. In addition, there is epithelial erosion, frank ulceration, and mucosal haemorrhage. ${ }^{26}$

It appears that immune factors are important to DNCB-induced colitis, as animals must be presensitised to develop colitis, ${ }^{2}$ the sensitivity can be passively transferred by lymphocytes, ${ }^{7}$ and immunosuppression will mitigate the bowel injury. ${ }^{8}$ There are, however, few data regarding the local immune apparatus in the model. We, therefore, investigated the lamina propria lymphocytes of guinea-pigs with DNCB-induced colitis and controls and determined the percentages of erythrocyte-rosetting cells ( $T$ cells), as well as the ability of the lamina propria lymphocytes to mediate mitogen-induced cellular cytotoxicity, a function of the $T$ cell. We also examined lymphocytes from mesenteric lymph node and spleen of the same animals.

The data show distinct differences between colitis and control animals with regard to lamina propria lymphocyte populations, but not spleen or mesenteric lymph node lymphocytes. We speculate that lamina propria lymphocytes may be involved in the tissue damage occurring in this condition. 


\section{Methods}

ANIMAL MODEL

Colitis was induced by a modification of a previously described regimen. ${ }^{2}$ Briefly, 10 adult male (500-700 g) Hartley guinea-pigs (Charles River Breeding Laboratories, Boston, Mass.) were sensitised by a single daily application to a shaved neck of $2 \%$ weightvolume DNCB-ethanol solution. After a rest period of a minimum of seven days, treatment-group animals received daily enemas with $0.25 \%$ DNCB suspended in mineral oil for 12-14 days. The suspension was prepared by dissolving the DNCB in an equal weight of acetone and suspending it in mineral oil. One control group of eight animals received DNCB skin sensitisation and daily enamas containing only mineral oil and acetone. A second control group of 11 animals received only skin sensitisation with DNCB and no enemas. Enemas were administered under ether anaesthesia and consisted of $10 \mathrm{ml}$ of mineral oil, delivered through an 8-French feeding tube attached to a syringe. The addition of radio-opaque media to the mineral oil allowed radiological demonstration that the suspension refluxed through the distal two-thirds of the guinea-pig colon.

The animals were killed after 12-14 days of daily enemas (or no enemas for the third control group) and the distal two-thirds of colon, as well as spleen and mesenteric lymph nodes, were removed and placed into medium at $4{ }^{\circ} \mathrm{C}$ (see below). Sections were taken from the colon for histological examination.

\section{MEDIA AND REAGENTS}

RPMI 1640 medium with glutamine was supplemented to $4 \mathrm{mM}$ glutamine, 100 units $/ \mathrm{ml}$ penicillin, and $100 \mu \mathrm{g} / \mathrm{ml}$ streptomycin (Grand Island Biological Company, Grand Island, New York), (RPMI-glutamine). In addition, 5\% fetal calf serum and $50 \mu \mathrm{g} / \mathrm{ml}$ gentamicin (Schering Corporation, Kenilworth, New Jersey) was added to RPMI 1640 medium and used for cell culture (RPMI-FCS). Fetal calf serum (Microbiological Associates, Bethesda, Maryland) was heat-inactivated $\left(56^{\circ} \mathrm{C}\right.$ for 30 minutes) before use. Eagle's minimal essential medium (Grand Island Biological) was supplemented with $10 \%$ fetal calf serum, $10 \%$ non-essential amino acids (Grand Island Biological), penicillin, and streptomycin as above (MEM).

PREPARATION OF LYMPHOCYTES Spleen and mesenteric lymph node lymphocytes Spleen and mesenteric lymph nodes were minced separately in petri dishes containing RPMI-glutamine. Single-cell suspensions were prepared by repeated, sequential aspiration of tissue fragments through 18, 20, and 21-gauge needles. The suspensions were allowed to settle at $4^{\circ} \mathrm{C}$ for five minutes. The supernatants were aspirated, centrifuged, at $900 \times g$ for 15 minutes and the cell pellet washed twice. The cells were suspended and purified by centrifugation over Ficoll-Hypaque (Pharmacia, Piscataway, New Jersey). The mononuclear cell layer was recovered, washed, and re-suspended in RPMI-FCS at a concentration of $10 \times 10^{6}$ cells $/ \mathrm{ml}$. This procedure yielded mononuclear cells with greater than $90 \%$ viability, as estimated by trypan blue exclusion.

\section{Lamina propria lymphocytes}

Lamina propria lymphocytes were obtained by a combined mechanical ${ }^{9}$ and enzymatic ${ }^{10}$ method. The distal two-thirds of the colon was removed and the lumen was flushed with $250 \mathrm{ml}$ saline. Segments of colon were filled with RPMI-glutamine, clamped at both ends, and gently rubbed until the walls became translucent. We removed intraluminal mucus and debris by irrigating the lumen with saline. The colon was opened, cut into $5-10 \mathrm{~mm}$ pieces and incubated for five hours with gentle stirring in RPMI-glutamine with $0.05 \mathrm{mg} / \mathrm{ml}$ collagenase (Worthington Biochemicals, Freehold, New Jersey) at $37^{\circ} \mathrm{C}$ in a humidified atmosphere of $5 \% \mathrm{CO}_{2}, 95 \%$ air. After incubation, the tissue fragments were allowed to settle and the cell-containing supernatant was aspirated, washed, re-suspended in RPMI-glutamine, layered over Ficoll-Hypaque, and centrifuged at $2250 \times g$ for eight minutes. The mononuclear cell layer was recovered, and washed twice. Viability was greater than $85 \%$, as estimated by trypan blue exclusion.

\section{Enumeration of rabbit erythrocyte-rosetting cells}

Guinea-pig $\mathrm{T}$ lymphocytes will form rosettes when incubated with rabbit red cells. ${ }^{11}$ We used the method described by Wilson and Coombs to assess this population in spleen, mesenteric lymph nodes, and colon lamina propria lymphocytes. A rosette was defined as three or more red cells adhering to a lymphocyte. At least 300 lymphocytes were counted and results were expressed as percent rosette-forming cells out of total lymphocytes counted.

\section{Cytotoxicity testing}

Mitogen-induced cell-mediated cytotoxicity was tested. P815 mouse mastocytoma tumour cells served as target cells. Target cells were maintained by sequential passage in MEM and were used when in the logarithmic growth phase 24-30 hours after passage. Target cells were labelled by incubating with $100 \mu \mathrm{C}$ sodium ${ }^{51}$ chromate (New England 
Nuclear, Boston, Mass., $300 \mu \mathrm{C} / \mathrm{mm}$ ) for 45 minutes at $37^{\circ} \mathrm{C}$. The cells were washed and suspended at a concentration of $2 \times 10^{5} / \mathrm{ml}$ in RPMI-FSC.

Mitogen-induced cellular cytoxicity (MICC) was measured in V-bottom microtitre plates (Cooke Laboratories, Alexandria, Virginia). Each 200 microlitre well contained $1 \times 10^{4}{ }^{51} \mathrm{Cr}-\mathrm{P} 815$ labelled target cells, mitogen, and lymphocytes (effectors). Mitogens included phytohaemagglutinin (PHA) (Burroughs-Wellcome, Triangle Park, New Jersey), or concanavalin-A (Con-A) (Sigma, St. Louis, Missouri). Preliminary studies were performed using target:effector cell ratios from $1: 25$ to $1: 100$. A plateau of activity was evident at a ratio of $1: 50$. The ratio of target:effector cells used in subsequent experiments was 1:50. PHA concentrations ranging from $5-20 \mu \mathrm{g} / \mathrm{ml}$ and concanavalin-A concentrations ranging from $3 \cdot 1-12 \cdot 4 \mu \mathrm{g} / \mathrm{ml}$ final concentrations were also tested. Optimal cytotoxicity was evident at $6.2 \mu \mathrm{g} / \mathrm{ml}$ PHA and $12.4 \mu \mathrm{g} / \mathrm{ml}$ Con-A. All assays were done in triplicate. Maximal releasable ${ }^{51} \mathrm{Cr}$ was determined by incubating $1 \times 10^{4}$ labelled target cells with $5 \%$ Triton X100. Spontaneous ${ }^{51} \mathrm{Cr}$ release was determined by incubation of target cells and mitogen without effector cells. Plates were centrifuged at $50 \times g$ for five minutes at $22^{\circ} \mathrm{C}$ and then incubated for 18 hours at $37^{\circ} \mathrm{C}$ in a humidified atmosphere of $5 \% \mathrm{CO}_{2}, 95 \%$ room air. Plates were harvested by centrifuging at $900 \times g$ for 10 minutes at $4^{\circ} \mathrm{C}$. One hundred microlitres of culture supernatant were counted in a liquid scintillation counter.

Cytotoxicity was expressed as percent specific target cells lysis, calculated by the following formula: $\%$ specific lysis $=$

$$
\begin{aligned}
& \text { experimental }{ }^{51} \mathrm{Cr} \text { release- } \\
& \frac{\text { spontaneous }{ }^{51} \mathrm{Cr} \text { release }}{\text { maximal }{ }^{51} \mathrm{Cr} \text { release }-} \times 100 \\
& \text { spontaneous }{ }^{51} \mathrm{Cr} \text { release }
\end{aligned}
$$

where

experimental ${ }^{51} \mathrm{Cr}$ release $=$ target + mitogen + effector cell spontaneous ${ }^{51} \mathrm{Cr}$ release $=$ target + mitogen maximal ${ }^{51} \mathrm{Cr}$ release $=$ target + Triton $\times 100$

Maximal release was always greater than $25000 \mathrm{cpm}$, and spontaneous release, less than $20 \%$.

\section{STATISTICAL METHODS}

Analysis of variance (one way) was applied to determine the likelihood that differences among groups could result by chance. A Hewlett Packard HP 67 computer was used to perform the tests.

\section{Results}

\section{DNCB-INDUCED COLITIS}

All 10 animals receiving DNCB enemas developed colonic inflammation. On gross examination, the serosal surface of the colon was erythematous with marked venous engorgement. Histologically, the lesion was characterised by mucosal and submucosal acute and chronic inflammation. There was epithelial cell degeneration, and a prominent perivascular mononuclear infiltration (Figure). These features are

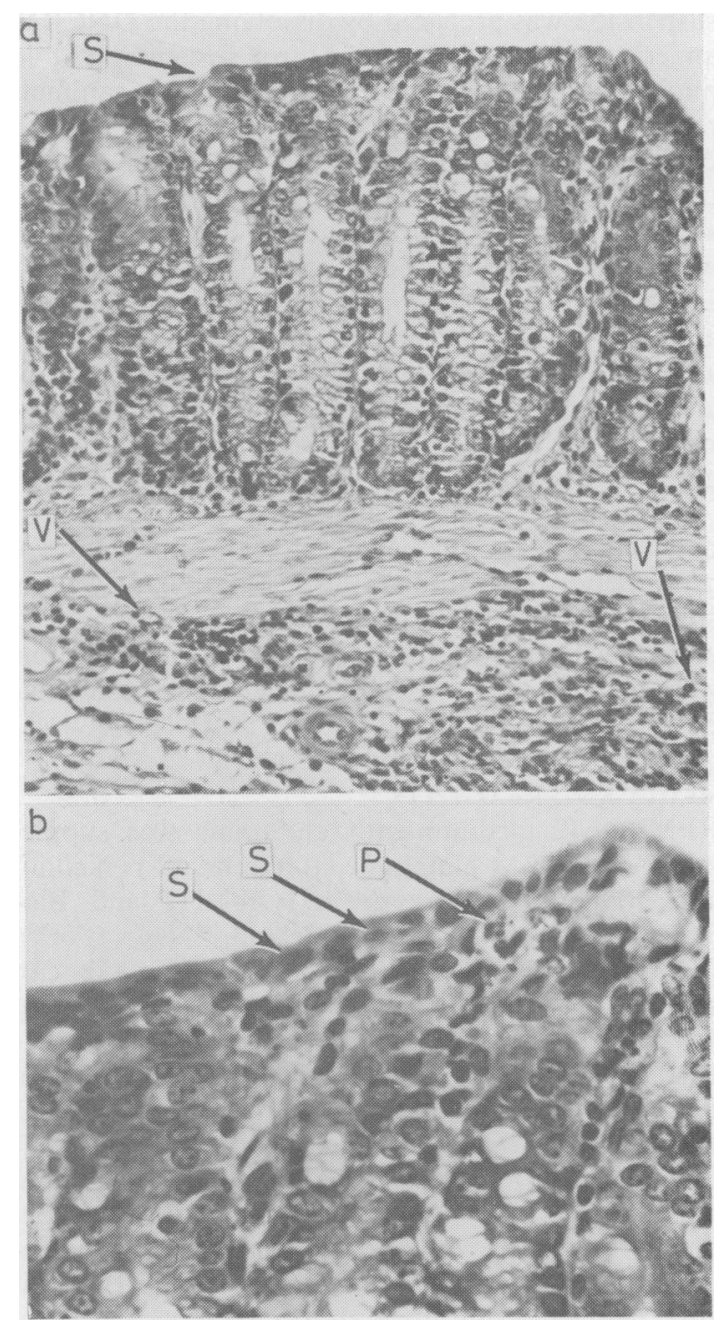

Figure Colonic mucosa from animal with DNCB colitis. The surface epithelium $(S)$ is markedly abnormal with loss of goblet cells, change to cuboidal character and presence of polymorphonuclear leukocytes $(P)$; in the submucosa, there is perivascular cuffing and infiltration by mononuclear cells $(V)$. (Original magnification $(a) \times 120$ and $(b) \times 400$ ). 
similar to those noted by others studying this model. All eight animals receiving DNCB skin sensitisation followed by only mineral oil enemas, as well as 11 animals receiving only skin sensitisation without enemas, had grossly and histologically normal colons with normal columnar epithelial cells and normal submucosal vessels.

\section{E-ROSETTING LYMPHOCYTES}

The percentage of rosette-forming lymphocytes in spleen and mesenteric lymph node (MLN) of animals with DNCB colitis was not significantly different from the percentage of rosette-forming lymphocytes in animals given no enemas or mineral oil enemas alone (Table 1). The percentage of rosette-forming cells in the spleen and mesenteric lymph nodes was also compared with the value for rosette-forming cells in peripheral blood lymphocytes obtained by a cardiac puncture in five animals (Table 1). Values for rosette-forming cells in peripheral blood lymphocytes were not significantly different from those of spleen or mesenteric lymph nodes.

In contrast with spleen, mesenteric lymph nodes,

Table 1 Rosette-forming cells in various lymphocyte populations

\begin{tabular}{lrllll}
\hline $\begin{array}{l}\text { Experimental } \\
\text { Group }\end{array}$ & no. & \multicolumn{4}{l}{ Lymphocyte population } \\
\cline { 3 - 5 } & & Spleen & $P B L^{*}$ & MLN† & Colon \\
\hline $\begin{array}{l}\text { Controls } \\
\quad \text { No enemas }\end{array}$ & 11 & $24 \cdot 7 \pm 3 \cdot 1 \ddagger 20 \cdot 1 \pm 1$ & $29 \cdot 3 \pm 2 \cdot 1$ & $2 \cdot 8 \pm \cdot 8 \S$ \\
$\quad \begin{array}{llll}\text { Mineral } \\
\text { oil enemas }\end{array}$ & 8 & $23 \cdot 6 \pm 1 \cdot 5$ & ND & ND & $3 \cdot 4 \pm \cdot 5 \S$ \\
DNCB enemas & 10 & $22 \cdot 6 \pm 2 \cdot 6$ & $25 \cdot 2 \pm 6 \cdot 3$ & $23 \cdot 5 \pm 3 \cdot 2$ & $20 \cdot 1 \pm 3 \cdot 0$ \\
\hline
\end{tabular}

*PBL: peripheral blood lymphocytes, five animals from each group were tested.

†MLN: mesenteric lymph node.

$\ddagger \%$ mean \pm SE.

$\S$ Difference between colon and other populations in same group is significant at $\mathbf{P}<0.01$ (analysis of variance, one way, four groups or two groups, respectively).

\|Difference between DNCB colon and other colon populations is significant at $P<0.01$ (analysis of variance, one way, three groups).

ND: not done. and peripheral blood, rosette-forming lymphocytes were present in much lower numbers in the normal colon lamina propria lymphocyte population $(2 \cdot 3 \pm$ $0.8 \%$ ). However, in the presence of DNCB-induced colitis, rosette-forming lymphocytes increased significantly to a value of $20 \cdot 1 \pm 2 \cdot 0 \%$ of the colon lamina propria lymphocytes $(\mathrm{P}<0.01)$.

MITOGEN-INDUCED CELLULAR CYTOTOXICITY Spleen and mesenteric lymph node lymphocytes mediate mitogen-induced cellular cytotoxicity with either PHA or Con-A as the mitogen. Furthermore, the cytotoxic activity was the same whether the lymphocytes came from animals with or without colitis (Table 2). In contrast, MICC values for lamina propria lymphocytes were greatly influenced by DNCB-induced colitis. Thus, while lamina propria lymphocytes from normal colon or colon subjected to mineral oil enemas alone did not mediate mitogen-induced cellular cytotoxicity (values less than $5 \%$ ), lamina propria lymphocytes from colons demonstrating DNCB colitis were capable of mediating mitogen-induced cellular cytotoxicity (Table 2). The cytotoxicity, with PHA as the mitogen, was significantly greater in lamina propria lymphocytes from DNCB-treated colons $v s$ control $(\mathbf{P}<0.005)$ and not different from that of spleen or mesenteric lymph node lymphocytes. The cytotoxicity observed with concanavalin $\mathrm{A}$ as the mitogen was also increased over control, but this difference was not statistically significant $(P<0 \cdot 1)$ (Table 2).

\section{Discussion}

Several observations strongly implicate involvement of the lymphocyte in the mucosal injury which occurs in DNCB colitis: (1) animals receiving rectal instillation of DNCB do not develop a prompt colitis unless previously sensitised by application of DNCB to skin ;2 (2) sensitivity to rectal instillation of DNCB can be induced by passive transfer of

Table 2 Mitogen-induced cell-mediated cytotoxicity of various lymphocyte populations

\begin{tabular}{|c|c|c|c|c|c|c|c|}
\hline \multirow[t]{3}{*}{ Experimental group } & \multirow[t]{3}{*}{ no. } & \multicolumn{6}{|c|}{ Lymphocyte population and mitogen } \\
\hline & & \multicolumn{2}{|l|}{ Spleen } & \multicolumn{2}{|l|}{$M L N$} & \multicolumn{2}{|l|}{ Colon } \\
\hline & & $P H A^{*}$ & Con-A† & $P H A$ & Con- $A$ & $P H A$ & Con- $A$ \\
\hline \multicolumn{8}{|l|}{ Controls } \\
\hline $\begin{array}{l}\text { No enemas } \\
\text { Mineral oil enemas } \\
\text { DNCB enemas }\end{array}$ & $\begin{array}{r}11 \\
8 \\
10\end{array}$ & $\begin{array}{l}43 \cdot 8 \pm 8 \cdot 7 \ddagger \\
56 \cdot 4 \pm 4 \cdot 7 \\
42 \cdot 6 \pm 8 \cdot 6\end{array}$ & $\begin{array}{l}41 \cdot 0 \pm 11 \cdot 4 \\
55 \cdot 1 \pm 4 \cdot 2 \\
34 \cdot 1 \pm 9 \cdot 1\end{array}$ & $\begin{array}{l}22 \cdot 5 \pm 8 \cdot 3 \\
\text { ND } \\
32 \cdot 3 \pm 7 \cdot 9\end{array}$ & $\begin{array}{l}20 \cdot 2 \pm 8 \cdot 5 \\
\text { ND } \\
16 \cdot 7 \pm 7 \cdot 4\end{array}$ & $\begin{array}{l}5 \cdot 0 \pm 4 \cdot 5 \\
-0 \cdot 7 \pm 4 \cdot 0 \\
29 \cdot 4 \pm 8 \cdot 7 \S\end{array}$ & $\begin{array}{r}3 \cdot 3 \pm 6 \cdot 4 \\
1 \cdot 9 \pm 3 \cdot 0 \\
17 \cdot 1 \pm 6 \cdot 5\end{array}$ \\
\hline
\end{tabular}

*PHA: phytohaemagglutinin.

+Con-A: concanavalin-A.

$\ddagger \%$ specific cytotoxicity (mean $\pm \mathrm{SE}$ ), see text for formula.

§DNCB: colon value is significantly greater than control colon values $(\mathrm{P}<0.005)$ (analysis of variance, one way, three groups). 
lymphocytes from a sensitised host; ${ }^{7}$ (3) DNCBinduced colitis can be mitigated by immunosuppression with intraperitoneal administration of azothiaprine, simultaneously with the rectal instillation of DNCB. ${ }^{8}$

The role in this model of circulating $v s$ the local lymphocyte is not clear. In the present studies, we determined that changes in number of rosetteforming cells and mitogen-induced cellular cytotoxicity occur in lamina propria lymphocytes, but not in systemic lymphocytes of animals with DNCB colitis. Lymphocytes have the property of 'homing' for a predetermined site in an organism. It is conceivable that the changes demonstrated in the LPL population would be reflected in similar changes in circulating lymphocytes were there not an overwhelming dilution effect due to the mass of lymphoid tissue in the entire organism.

We believe the following hypothesis may be operative in the DNCB colitis model: the skin sensitisation of the guinea-pig with DNCB establishes a population of lymphocytes immunised to this agent. During the repeated enemas, DNCB binds to the tissue protein of the colonic mucosa. DNCB-responsive lymphocytes infiltrate the lamina propria and are cytotoxic to the DNCB-bearing colonic mucosa. This mobilisation of the DNCBresponsive, locally activated lymphocyte population is reflected in an increase in lamina propria lymphocyte, rosette-forming cells ( $T$ cells), and an increase in mitogen-induced cellular cytotoxicity. The increased mitogen-induced cellular cytotoxicity may be both a reflection of increased numbers of $T$ cells or an increase in activation of the T cells. ${ }^{12} \mathrm{We}$ do not believe the differences noted between lamina propria lymphocytes of control animals versus lamina propria lymphocytes of DNCB colitis animals are a result of changes in the macrophage population. This belief is supported by the observation that macrophages do not appreciably mediate mitogen-induced cell-mediated cytotoxicity when cultured cell lines are used as the targets. ${ }^{13}$ In future experiments, the lamina propria lymphocyte population will be characterised in further detail.

It is possible, however, that the changes demonstrated in the lamina propria lymphocytes are not pathogenic of mucosal injury, but merely a phenomenon secondary to inflammation with non-specific T-cell recruitment. ${ }^{14}$ Against this possibility, is the observation that a control group of animals receiving mineral-oil enemas alone demonstrated neither histological nor immunological changes. In addition, the observation that DNCB-induced mucosal cell injury can be mitigated by immunosuppression suggests that the local immune apparatus serves at least as one of the mediators of mucosal injury, rather than as a secondary consequence of inflammation.

In conclusion, we have demonstrated that in the DNCB colitis model, mucosal injury is accompanied by evidence of alterations of the local immune apparatus as demonstrated by increased numbers of local $T$ cells and increased activity of mitogeninduced cellular cytotoxicity. We postulate that these changes in local lymphocytes may reflect the involvement of lamina propria lymphocytes in the tissue damage. Study of other models of colitis, especially models that are thought to be toxin or bacteriologically mediated, ${ }^{15}$ will help clarify whether changes in lamina propria lymphocytes shown here are specific to the DNCB model or are a nonspecific response to colonic inflammation.

The authors wish to thank Joyce Masters for her expert technical assistance and Janis Bongiovanni for her assistance in the preparation of this manuscript.

\section{References}

${ }^{1}$ MacPherson B, Pfeiffer CJ. Experimental colitis. Digestion 1976; 14: 424-52.

${ }^{2}$ Bicks RO, Rosenberg EW. A chronic, delayed hypersensitivity reaction in the guinea pig colon. Gastroenterology 1964; 46: 543-9.

${ }^{3}$ Watts J, Marcus R. Carrageenan-induced ulceration of the large intestine in the guinea pig. Gut 1971; 12: 164-71.

${ }^{4}$ Marcus R, Watts J. Ulcerative disease of the colon in laboratory animals induced by pepsin inhibitors. Gastroenterology 1974; 67: 473-83.

${ }^{5}$ Hodgson HJF, Potter BJ, Skinner J, Jewell DP. Immune-complex mediated colitis in rabbits. An experimental model. Gut 1978; 19: 225-32.

${ }^{6}$ Rabin BS, Rogers SJ. A cell-mediated immune model of inflammatory bowel disease in the rabbit. Gastroenterology 1978; 75: 29-33.

'Bicks RO, Azar MM, Rosenberg EW, Dunham WG, Luther J. Delayed hypersensitivity reactions in the intestinal tract. I. Studies of 2, 4-dinitrochlorobenzenecaused guinea pig and swine colon lesions. Gastroenterology 1967; 53: 422-36.

${ }^{8}$ Bicks RO, Brown G, Hicky D, Rosenberg EW. Further observations on a delayed hypersensitivity reaction in the guinea pig colon. Gastroenterology $1965 ; 48$ : 425-9.

${ }^{9}$ Arnaud-Battandier F, Bundy BM, O'Neill N, Bienenstock J, Nelson DL. Cytotoxic activities of gut mucosal lymphoid cells in guinea pigs. J Immunol 1978; 121 : 1059-65.

${ }^{10}$ Bull D, Bookman MA. Isolation and functional characterization of human intestinal mucosal lymphoid cells. J Clin Invest 1977; 59: 966-74.

${ }^{11}$ Wilson AB, Coombs RRA. Rosette formation between guinea pig lymphoid cells and rabbit erythrocytesa possible T-cell marker. Int Arch Allergy 1973; 44: $544-52$. 
${ }^{12}$ Wisloff F, Froland SS, Michaelson TE. Characterization of sub-populations of human lymphoid cells participating in phytohemagglutinin and concanavalin-A induced cytotoxicity. Int Arch Allergy 1974; 47: 488-97. ${ }^{13}$ Nelson DL, Bundy BM, Pitchon HE, Blaese MR, Strober W. The effector cells in human peripheral blood mediating mitogen-induced cellular cytotoxicity and antibody-dependent cellular cytotoxicity. J Immunol 1976; 117: 1472-81.
${ }^{14}$ Asherson GL. The role of $\mathrm{T}$ cells in inflammation: activated $\mathrm{T}$ cells which move to sites of inflammation and suppressor $\mathrm{T}$ cells which depress contact sensitivity, In: Velo GP, Willoughby DA, Giroud JP, eds. Future trends in inflammation, Padua: Piccin Medical Books: $1973 ; 331-42$.

${ }^{15}$ Onderdonk AB, Hermos JA, Dzink J, Bartlett JG. Protective effect of metronidazole in experimental ulcerative colitis. Gastroenterology 1978; 74: 521-6. 